\title{
Planos para ampliação da divulgação das ciências da saúde
}

Plans to expand the dissemination of health sciences

Vitor Engrácia Valenti

Foi com muito prazer que recebi o convite do editor chefe dos Arquivos Brasileiros de Ciências da Saúde, o professor doutor Ricardo Peres do Souto, para participar como membro do corpo editorial desta prestigiada revista. De imediato aceitei o convite, na expectativa de poder contribuir para o progresso constante desse importante meio de comunicação.

Em 1978 foi publicado o primeiro número da revista, inicialmente denominada “Arquivos Médicos do ABC”. Desde então, o corpo editorial tem realizado imensos esforços com o objetivo de colaborar na permutação de conhecimentos adquiridos, bem como na divulgação da ciência. Tal condição exige constante contato com maior número de profissionais das áreas da saúde. A revista teve sucesso no decorrer desses 40 anos, na árdua caminhada para divulgar amplamente a produção técnico-científica, a qual abrange tópicos de extrema relevância para a saúde. Desse modo, os Arquivos Brasileiros de Ciências da Saúde busca a harmonia e a sintonia das diferentes áreas disciplinares. Ademais, é também objetivo da revista o acolhimento de trabalhos de distintas origens acadêmicas.

Na condição de membro do corpo editorial dos Arquivos Brasileiros de Ciências da Saúde, a principal meta é manter o sucesso da revista e aumentar sua visibilidade. Tendo em vista a evolução científica pela qual o Brasil passa, torna-se necessário a indexação dos Arquivos Brasileiros de Ciências da Saúde em um amplo número de bases de dados. Tal fato colabora para a maior divulgação do conteúdo da revista. Tratando-se de uma revista arbitrada e aberta a contribuições da comunidade científica nacional e internacional, reitera-se o comprometimento com a divulgação e a difusão de produção científica na área de ciências da saúde.

Para maior visibilidade da revista, torna-se fundamental a indexação da revista em bases de dados internacionais, de modo com que pesquisadores, estudantes e todos aqueles envolvidos com ciência no mundo inteiro tenham acesso às informações divulgadas pelos estudos publicados nesta revista.

Assim, convidamos pesquisadores e autores da área da saúde a participarem ativamente nesse percurso desafiador. 